\title{
$\mathrm{AE}$ 센서와 신경회로망을 이용한 NAK80 금형강의 자기연마 가공특성 모니터링 \\ 김광희 ${ }^{+}$, 신창민 ${ }^{++}$, 김태완 ${ }^{++}$, 곽재섭*
}

(Manuscript received: Dec, 15, 2011 / Revised: Jan, 31, 2012 / Accepted: Jan, 31, 2012)

\section{Surface Condition Monitoring in Magnetic Abrasive Polishing of NAK80 Using AE Sensor and Neural Network}

\author{
Kwang-Heui $\mathrm{Kim}^{+}$, Chang-Min Shin ${ }^{++}$, Tae-Wan Kim ${ }^{++}$, Jae-Seob Kwak*
}

\begin{abstract}
The magnetic abrasive polishing (MAP), for online monitoring with AE sensor attachment, was performed in this study. To predict the surface roughness after the magnetic abrasive polishing of NAK80, the signal data acquired from the AE sensor were analyzed. A dimensionless coefficient, which consisted of average of AErms and standard deviation of AE signal, was defined as a characteristic of the MAP and a prediction model was obtained using least square method. A neural network, which had multiple input parameters from AE signals and polishing conditions, was applied for predicting the surface roughness. As a result of this study, it was seen that there was very close correlation between the AE signal and the surface roughness in the MAP. And then on-line prediction of the surface roughness after the MAP of the NAK80 was possible by the developed prediction model.
\end{abstract}

Key Words : Acoustic emission(음향방출), Dimensionless coefficient(무차원계수), Magnetic abrasive polishing(자기연마), Neural network(신경회로망), Process parameter(공정변수), Surface roughness(표면거칠기)

\section{1. 서 론}

정밀한 기계부품에 적용되는 금속재료는 점차 난삭화 되어 가공에 어려움이 따른다. 이에 따라 난삭 재료들의 가공기술에 대한 연구가 활발히 진행되고 있다. 그 중 NAK80 금형강은 우수한 용접성과 높은 표면경도, 안정성 등의 장점으로 정밀금 형에 적합하여 사출성형, 정밀 플라스틱 금형과 프레스 금형 등 금형 산업에서 많이 사용되는 소재이다 ${ }^{(1)}$. 이런 난삭 소재의
가공은 주로 연삭가공에 의해 이루어지는데 금형의 복잡한 형 상 때문에 연삭숫돌의 제작이 어렵고, 일반적인 연삭가공으로 는 균일한 표면을 얻기가 매우 힘들다. 이를 해결하기 위한 방 안으로 전자석을 이용한 자기연마법을 적용하였다. 전자석으 로 구성된 인덕터에 전류가 부가되면 자기력이 형성된다. 이 때 인덕터와 가공물의 간극에 연마입자와 자성입자를 혼합한 자기연마입자를 공급하면 자기장에 의해 브러쉬 형상의 공구 를 형성한다. 브러쉬 형상의 공구는 유연성을 가지기 때문에

\footnotetext{
* 부경대학교 기계공학과 (jskwak5@pknu.ac.kr) 주소: 부산 남구 용당동 산 100 번지

$+\quad$ 부경대학교 기계자동차공학과

$++\quad$ 부경대학교 기계공학과
} 
가공물의 표면형상에 상관없이 연마가 가능하다 ${ }^{(2)}$. 이러한 자 기연마의 연마효율을 평가하기 위해서는 측정기술이 필요한데, 측정의 단계에서 가공물이 손상을 입거나 공정 시간이 증가하 게 된다. 이에 따라서 온라인 예측 시스템을 구축하고자 하였 다. 자기연마에서는 연마입자와 가공물이 접촉할 때의 마찰에 의해서 신호가 발생하는데, 이는 매우 높은 주파수 영역의 신호 이다. 이를 획득하기 위한 방안으로 수 $\mathrm{MHz}$ 의 광범위한 주파 수 응답을 가지는 $\mathrm{AE}$ 센서를 활용하여 자기연마 공정에 모니 터링 시스템을 적용하고자 하였다.

본 논문에서는 금형강 소재인 NAK80의 자기연마의 특성인 표면거칠기 향상 값을 예측하기 위해서 자기연마 공정 중에 발 생하는 $\mathrm{AE}$ 신호를 획득 및 분석하고 자기연마 특성을 나타내 는 무차원계수를 정의하여 온라인(On-line)으로 표면거칠기 향 상 값의 예측이 가능한 예측식을 얻고 신경회로망의 역전파 학 습법을 활용하여 분석하고자 하였다.

\section{2. 이론적 배경}

\section{1 자기연마}

자기연마법은 전자석으로 구성된 자기연마헤드에 전류를 부 가하면 패러데이 법칙에 의해서 자기력이 발생한다. 그 때 자기 연마헤드와 가공물의 간극에 매개체를 통해서 연마입자와 자 성입자로 혼합된 자기연마입자를 슬러리 형태로 공급하면 자 성입자는 자기력에 의해 자기연마헤드에 구속되고 자기력선에 따라서 사슬구조로 정렬된다. 이 때 자성입자들 사이에 연마입 자들이 위치하면서 사슬구조로 형성된 브러쉬 형상의 공구가 형성된다. 이렇게 형성된 브러쉬 형상의 공구는 유연성을 가지 기 때문에 가공물의 형상에 상관없이 연마가 가능하다는 장점 을 가지고 있다. Fig. 1은 자기연마기의 개략도이다 ${ }^{(3)}$.

\section{2 음향방출법}

Fig. 2는 $\mathrm{AE}$ 시스템의 원리를 나타낸다. $\mathrm{AE}$ 시스템은 가공 물 외부에서 작용하는 힘에 의해 변형, 균열, 파괴 등이 발생할 때, 재료 내부에서 저장되어 있던 변형 에너지가 탄성파로 발생

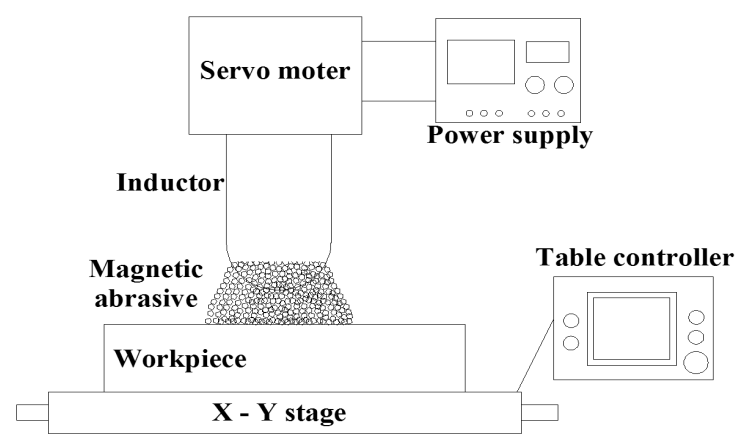

Fig. 1 Schematic diagram of MAP machine
되는 현상으로 이렇게 방출된 탄성파가 $\mathrm{AE}$ 센서를 통하여 전 기적 신호로 측정되고 가공물의 결함예측 및 판단이 가능하게 하는 시스템을 말한다. $\mathrm{AE}$ 신호는 불규칙적이고 비주기성을 가지는 신호이다. 그리고 센서를 통한 출력은 탄성파로 방출된 신호의 에너지 값을 가지고 있어 $\mathrm{AE}$ 신호 해석을 위해서는 에 너지 량인 실효치 전압(AErms) 값을 측정하는 것이 가장 적당 한 방법이고, 이는 식 (1)로 나타낼 수 있다.

$$
\text { AErms }=\sqrt{\frac{1}{\Delta T} \int_{0}^{\Delta T} V^{2}(t) d t}
$$

여기서 $V(t)$ 는 측정된 $\mathrm{AE}$ 신호이고, $\Delta T$ 는 $\mathrm{AErms}$ 값을 취하 는 평균 시간을 의미한다 ${ }^{(4)}$.

\section{3 신경회로망}

신경회로망은 인간의 기억이 신경망으로 구성되어 있고, 기억 내용들이 노드 사이의 연결 강도로 저장된다는 이론이다. 즉, 인 공신경망은 뇌기능의 특성 몇 가지를 컴퓨터 시뮬레이션으로 표 현하는 것을 목표로 하는 수학 모델이다. 뉴럴 네트워크는 인간 두뇌의 신경세포를 모방한 개념으로 시냅스(Synapse)의 결합에 의해서 네트워크를 형성한 인공 뉴런(Neuron)이 학습을 통해 시냅스의 결합 세기를 변화시켜, 문제 해결 능력을 가지는 모델 전반을 가리킨다. 과거에 수집된 데이터로부터 반복적인 학습과 정을 거쳐 데이터에 내재되어 있는 패턴을 찾아내는 모델링 기 법으로 여러 가지 현상에 대한 적절한 판단을 유도하기 위한 것 이다. 그 중에서 역전파 학습법은 입력층과 출력층 사이에 하나 이상의 은닉층을 가지는 다층 구조의 회로망이며, 전달함수로는 주로 비선형인 시그모이드 함수가 사용된다 ${ }^{(5)}$.

\section{3. 실험방법 및 결과}

\section{1 실험방법}

금형강인 NAK80 소재의 자기연마 가공에서 자기연마의 특

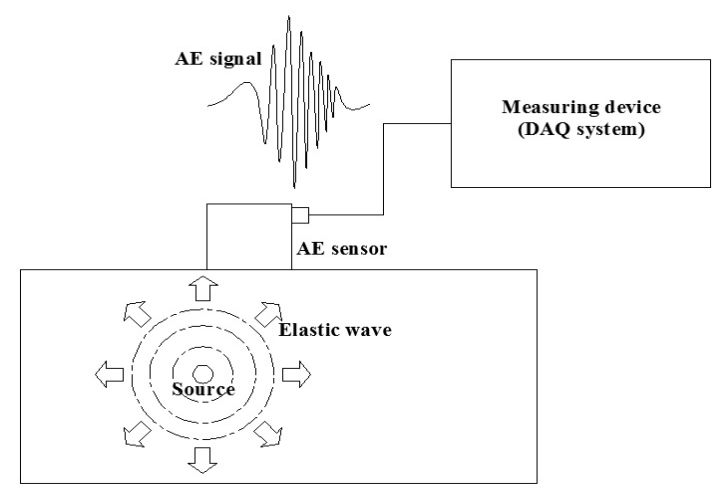

Fig. 2 Principle of acoustic emission method 
성을 나타내는 표면거칠기 값과 획득된 $\mathrm{AE}$ 신호의 상관성을 얻 기 위해서 공정변수에 따른 자기연마 실험을 실시하였다. Fig. 3 은 자기연마기에 음향방출 시스템을 설치한 개략도를 나타내 었다. 자기연마의 공정변수로는 기초연구에 의해 자기연마에 많 은 영향을 주는 공구의 회전속도, 간극, 인덕터의 전류 3 가지를 선택하였고, 각각의 조건에 따른 결과를 분석하기 위해 두 가지 변수는 최적조건으로 설정하는 방법으로 총 7번의 실험을 진행 하였다. 자기연마 실험조건은 Table 1에 나타내었다. $\mathrm{AE}$ 센서 를 활용한 모니터링 시스템은 잡음에 강하고 넓은 주파수 범위 에서도 균일한 감도를 나타내는 $\mathrm{PAC}$ 사의 광대역형 $\mathrm{AE}$ 센서 $(100 \sim 750 \mathrm{kHz})$ 를 사용했고, 자기연마가공 공정에서 발생되는 $\mathrm{AE}$ 신호는 매우 작은 신호이기 때문에 전치증폭기(Pre-amplifier) 를 통해 $60 \mathrm{~dB}$ 로 증폭되어진다. 그리고 $\mathrm{A} / \mathrm{D}$ 변환기에 의해 디지털 신호로 변환되어 LabVIEW를 통해 데이터가 저장되고, 대역필터 (Band-pass filter)로 필터링이 진행된다. 자기연마 공정 중에 발생 되는 신호는 고주파 영역의 신호이기 때문에 고속샘플링이 가능한 NI사의 PCI-6132 A/D 변환기를 사용하였고, $2 \mathrm{MS} / \mathrm{s}$ 의 속도로 데 이터를 획득했다. 여기서 $\mathrm{AE}$ 센서는 고진공 그리스를 사용하여 가 공물에 압착시키고, 폴리우레탄 접착제로 1 차 고정 후에 실험을 위해 제작된 지그(Jig)를 사용하여 2차 고정하였다.

\section{2 실험결과}

본 연구에서 자기연마 특성치는 연마된 가공물의 표면거칠기 향상 값을 사용하였다. 표면거칠기 향상 값은 가공 전 표면거칠

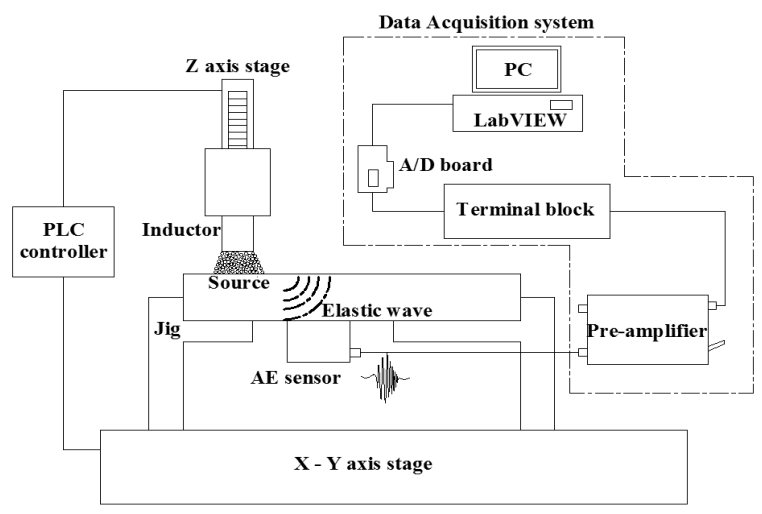

Fig. 3 Schematic diagram of the acoustic emission system

Table 1 Experimental conditions

\begin{tabular}{l|c}
\hline \hline Items & Conditions \\
\hline Workpiece & NAK80 $(80 \times 40 \times 20 \mathrm{t})$ \\
\hline Spindle speed $(\mathrm{rpm})$ & $800,1000,1200$ \\
\hline Working gap $(\mathrm{mm})$ & $1.0,1.5,2.0$ \\
\hline Current of inductor $(\mathrm{A})$ & $1.5,2.0,2.5$ \\
\hline Working time $(\mathrm{min})$ & 5 \\
\hline Magnetic abrasive & Iron $+\mathrm{CBN}(\# 3000)+$ silicone gel \\
\hline
\end{tabular}

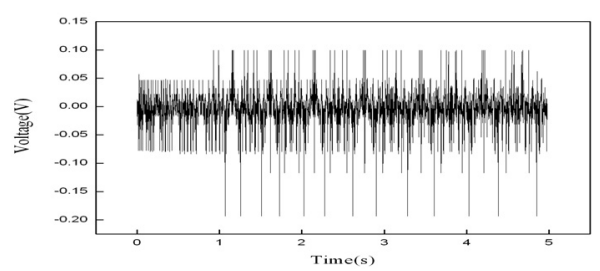

(a) Experiment no. 1

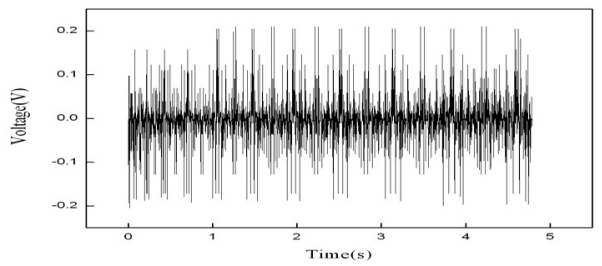

(b) Experiment no. 2

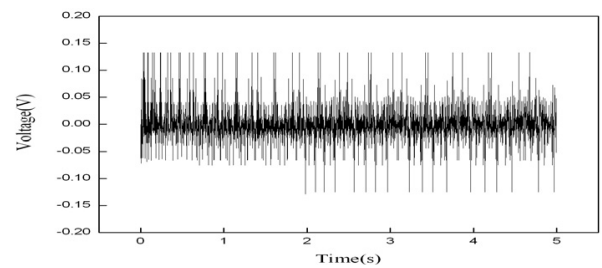

(c) Experiment no. 3

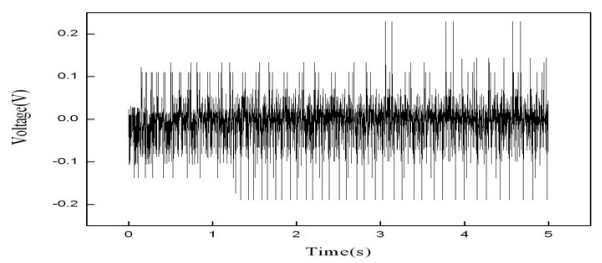

(d) Experiment no. 4

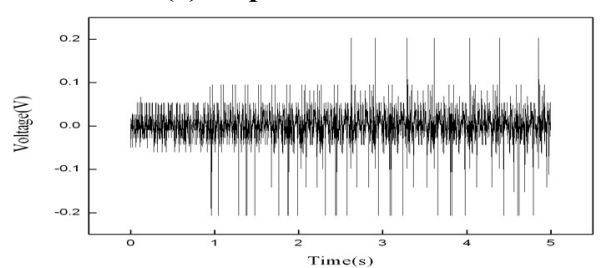

(e) Experiment no. 5

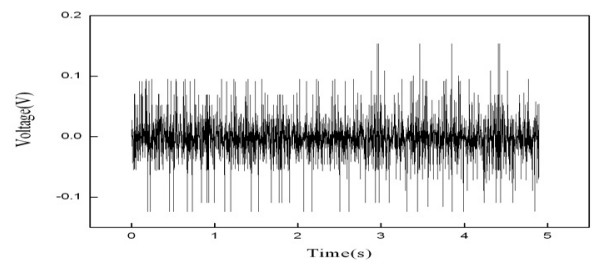

(f) Experiment no. 6

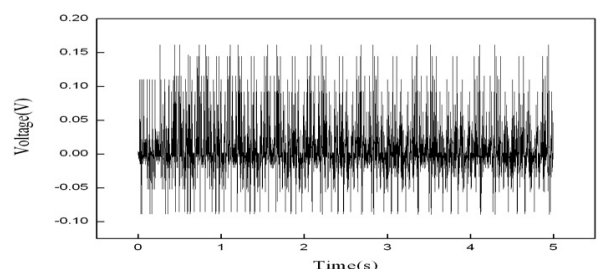

(g) Experiment no. 7

Fig. 4 AE raw signal of MAP experiments 


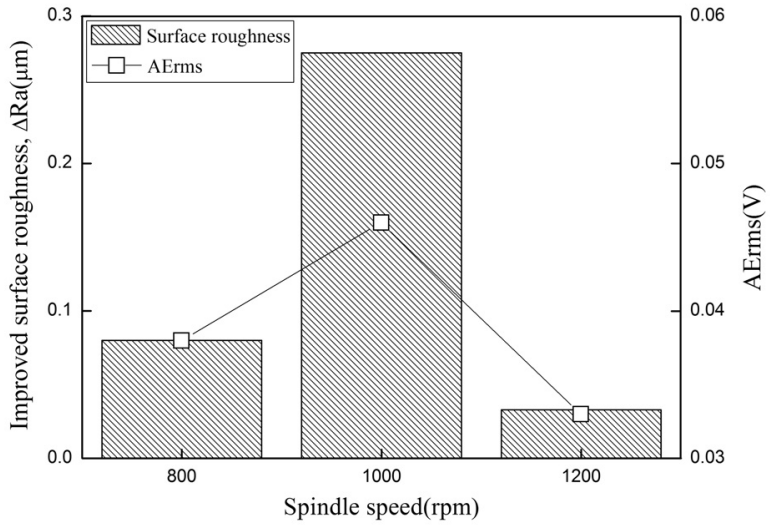

Fig. 5 Results according to spindle speed

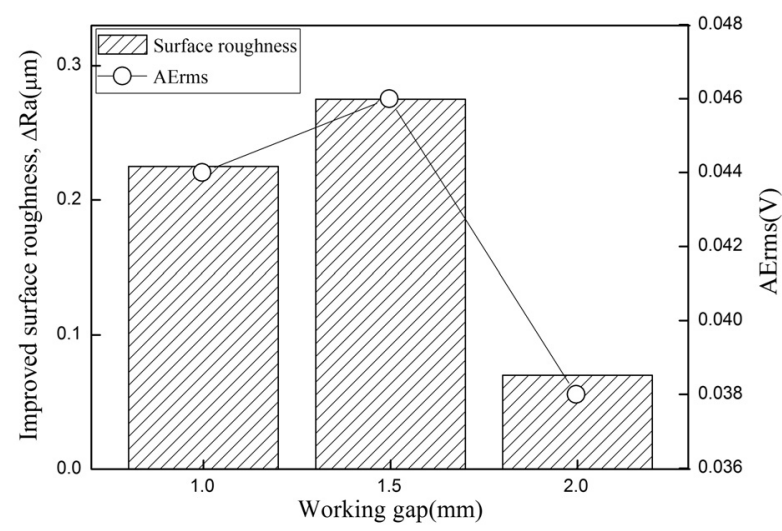

Fig. 6 Results according to working gap

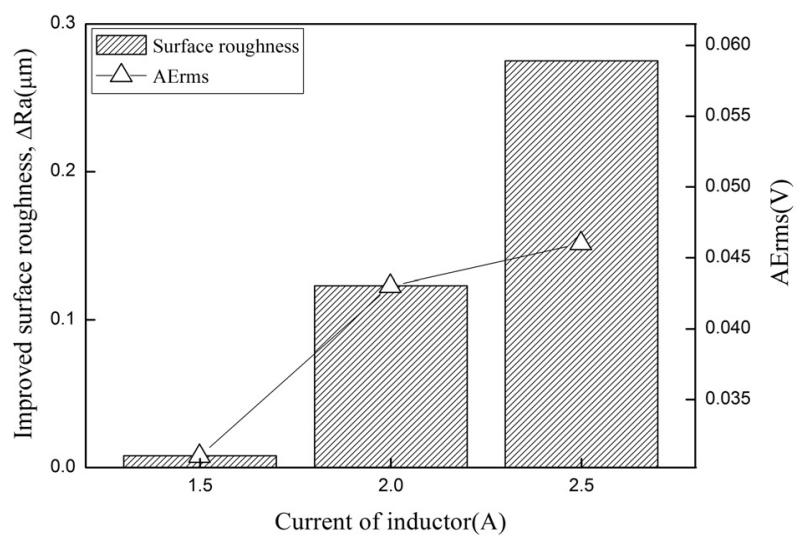

Fig. 7 Results according to current of inductor

기 값과 가공 후 표면거칠기 값의 차를 의미한다. 획득된 $\mathrm{AE}$ 원신호는 연속신호로 불규칙적이고 비주기성의 신호이기 때문 에 정량적인 분석이 매우 어렵다. 그래서 획득한 $\mathrm{AE}$ 신호의 정량적인 분석을 위해서 $\mathrm{AE}$ 신호의 에너지량을 의미하는 실효 치 전압 값을 사용하였다. 전체적인 AErms 값을 분석했을 때 가공 후반으로 갈수록 RMS 값이 점점 줄어드는 것을 확인할 수가 있는데, 이는 일반적인 가공특성에 따라 시간이 지날수록
절삭력이 점차적으로 감소하기 때문이다. Fig. 4는 가공조건에 따른 $\mathrm{AE}$ 원신호를 나타내었다. Fig. 5는 공구 회전속도에 따른 표면거칠기 향상 값과 $\mathrm{AErms}$ 평균값으로 $1,000 \mathrm{rpm}$ 일 때 $0.275 \mu \mathrm{m}$ 로 가장 큰 표면거칠기의 향상이 나타나며 AErms의 평균값 또한 0.046 으로 가장 큰 값을 나타내었다. Fig. 6은 간 극에 따른 표면거칠기 향상 값과 AErms 평균값이고, Fig. 7은 인덕터에 인가되는 전류에 따른 표면거칠기 향상 값과 AErms 평균값을 나타내었다. 공구 회전속도는 $1,000 \mathrm{rpm}$ 에서 간극은 $1.5 \mathrm{~mm}$ 그리고 인덕터에 부가되는 전류는 $2.5 \mathrm{~A}$ 에서 가장 큰 표면거칠기 향상이 나타났다. 표면거칠기의 향상 값이 증가할 수록 AErms의 평균값 또한 증가한다는 것을 나타내었다. 즉, 분석된 $\mathrm{AErms}$ 평균값은 자기연마 특성인 표면거칠기 향상 값 과 정량적인 상관성을 가진다는 것을 확인하였다.

\section{4. 표면거칠기 예측모델 개발}

\subsection{AE 신호를 이용한 온라인 예측시스템}

자기연마 특성인 표면거칠기 향상 값을 예측하기 위한 $\mathrm{AE}$ 파라메터로는 획득한 $\mathrm{AE}$ 신호의 에너지량인 $\mathrm{AErms}$ 평균값과 획득한 $\mathrm{AE}$ 데이터 값들이 평균으로부터 떨어진 정도를 나타내 는 표준편차를 사용하여 표면거칠기 향상 값과 직접적인 상관 성을 나타내는 무차원계수 $\left(\phi_{A E M A P}\right)$ 를 식 (2)로 정의했다.

$$
\begin{aligned}
\phi_{A E M A P}= & \frac{\text { Average of AErms }}{\text { Standarddeviation }} \\
& =\frac{\frac{1}{k} \sum_{j=1}^{k} \text { AErms }_{j}}{\sqrt{\frac{1}{n} \sum_{i=1}^{n}\left(\bar{x}-x_{i}\right)^{2}}}
\end{aligned}
$$

여기서 $n$ 은 $\mathrm{AE}$ 신호의 전체 데이터 수, $A E r m s_{j}$ 는 0.5 초 간격 으로 분석한 $\mathrm{AErms}$ 평균값, $k$ 는 $\mathrm{AErms}$ 를 취한 개수, $\bar{x}$ 는 $\mathrm{AE}$ 신호의 평균값, $x_{i}$ 는 $\mathrm{AE}$ 신호의 값을 나타낸다. 즉 무차원계수 는 $\mathrm{AE}$ 신호의 에너지 평균값에 대한 표준편차의 비를 의미한다. 정의된 무차원계수를 선형 최소자승법에 적용하여 자기연마 의 특성인 표면거칠기 향상 값을 예측하기 위한 예측식을 식 (3)과 같이 얻을 수 있었다.

$$
p(x)=-1.21 \times \phi_{A E M A P}+1.543
$$

Fig. 8은 $\mathrm{AE}$ 신호의 무차원계수를 이용하여 예측한 표면거 칠기 향상 값과 측정을 통해서 얻어진 측정값을 비교한 그래프 이다. 이 때 측정값과 예측값의 최대 오차율은 대부분 $5 \%$ 이내 를 나타내었기 때문에 자기연마 가공 표면의 표면거칠기 향상 


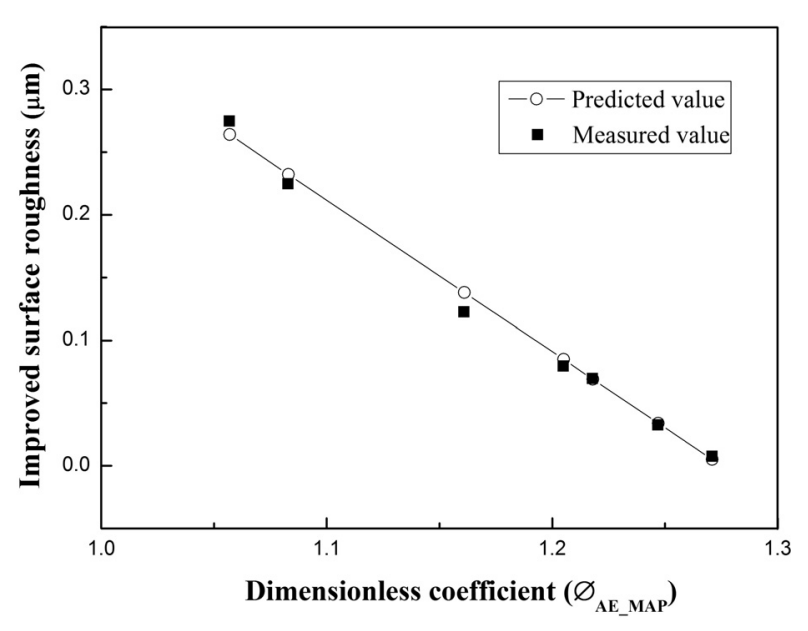

Fig. 8 Comparison of measured and predicted values

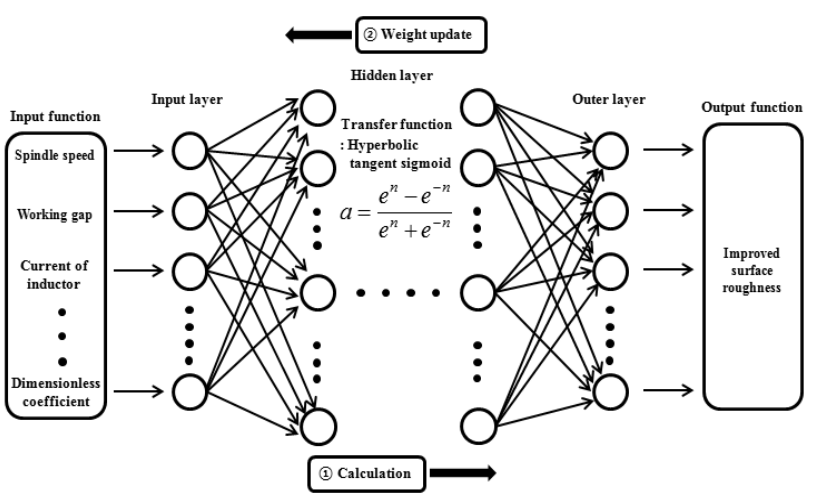

Fig. 9 Configuration of the back-propagation algorithm

값은 온라인 예측이 가능함을 알 수 있었다.

\section{2 신경회로망을 이용한 표면거칠기 예측}

$\mathrm{NAK} 80$ 금형강 소재의 자기연마 공정 효과를 분석하기 위한 방안으로 신경회로망의 역전파 알고리즘을 사용하였다 ${ }^{(6-7)}$. 자 기연마 공정변수와 $\mathrm{AE}$ 신호 특성인 무차원계수 그리고 자기연 마 공정변수와 무차원계수를 함께 사용하여 각각의 입력함수 로 선정하였고, 표면거칠기 향상 값을 목표값으로 선정하여 분 석하였다. 전달함수로는 쌍곡선 탄젠트 시그모이드 함수를 사 용하였다. Fig. 9는 본 연구에 사용된 역전파 학습의 개략도이다.

신경회로망 분석은 자기연마 공정변수와 정의된 무차원계수 를 입력함수로 하고, 표면거칠기 향상 값을 목표값으로 선정하 였다. 공정변수를 입력함수로 사용했을 때 상관계수 R은 0.99966 을 나타내었고, 166 번째 반복에서 목표값에 수렴하였다. 무차 원계수를 입력함수로 사용했을 때 상관계수는 0.99997을 나타 내었고, 98 번째 반복에서 목표값에 수렴하였다. 그리고 공정변 수와 무차원계수를 동시에 입력함수로 사용했을 때 상관계수 는 1 에 가까운 값을 나타내었고, 62 번째에서 수렴한다는 것을 확인할 수 있었다. 그 결과로 입력함수에 따른 분석은 모두 높

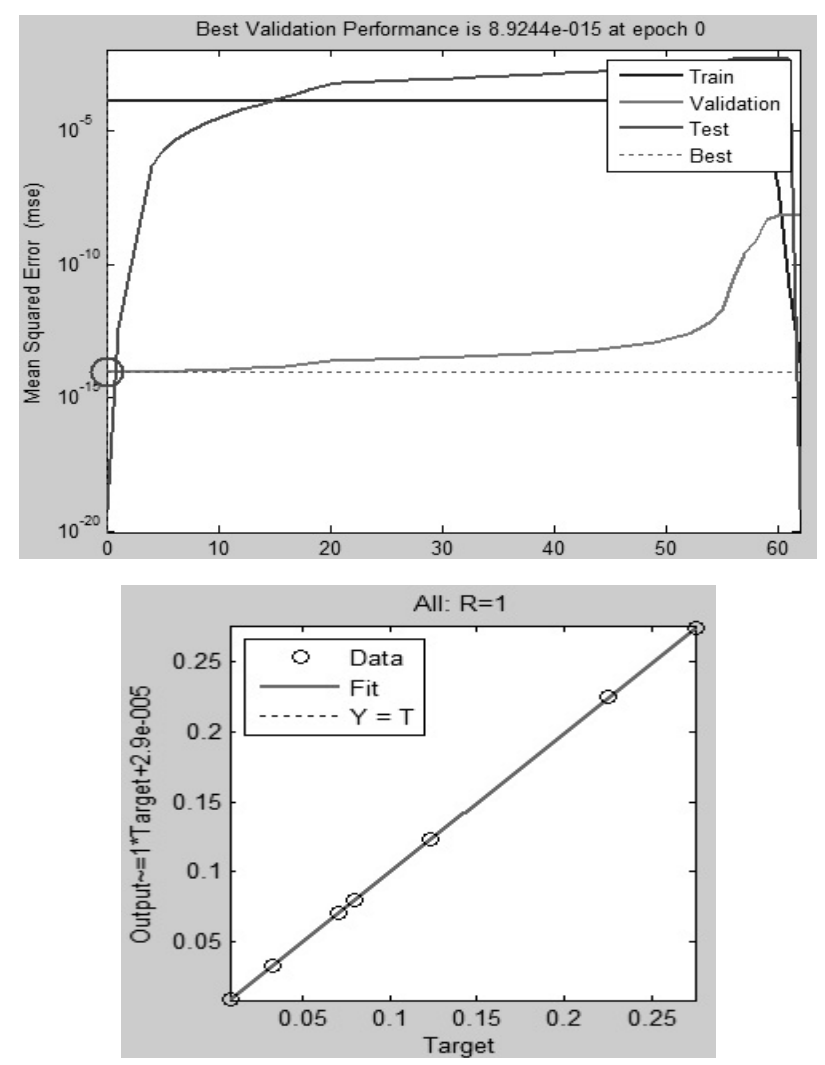

Fig. 10 Mean square error and regression (process parameters and dimensionless coefficient)

Table 2 Condition of verification experiment

\begin{tabular}{c|c|c|c}
\hline \hline Exp. no. & Spindle speed (rpm) & Gap (mm) & Current (A) \\
\hline V-1 & 900 & 1.50 & 2.50 \\
\hline V-2 & 1000 & 1.25 & 2.50 \\
\hline V-3 & 1000 & 1.50 & 2.25 \\
\hline
\end{tabular}

은 신뢰수준을 나타내었다. 여기서 목표값에 수렴하기 위한 반 복횟수를 신경회로망의 효율로 판단하였고, 그 중 공정변수와 무차원계수를 동시에 입력함수로 사용한 경우 가장 빠른 수렴 횟수를 보였다. Fig. 10은 공정변수와 무차원계수를 동시에 입 력함수로 사용하여 분석한 평균 제곱 오차와 목표값과 출력값 의 회귀도를 나타내었다.

$\mathrm{AE}$ 모니터링 시스템의 유효성을 검증하기 위해서 3 번의 추 가 검증실험을 수행하였다. Table 2 는 검증실험을 위한 자기연 마의 가공조건을 나타내었다. Fig. 11은 자기연마 검증실험 중 에 발생되는 $\mathrm{AE}$ 원신호를 나타내었다. 검증실험을 통하여 측 정된 표면거칠기 향상 값과 제안된 예측식에 의해 계산한 예측 값을 비교했을 때, 오차율은 최대 $9.4 \%$ 로 모두 $10 \%$ 이내의 오 차율이 나타났다. Fig. 12는 측정값과 예측값을 비교해서 나타 낸 그래프이다. 그리고 검증실험을 통하여 획득된 $\mathrm{AE}$ 신호를 분석해서 얻어진 무차원계수와 공정변수를 동시에 입력함수로 


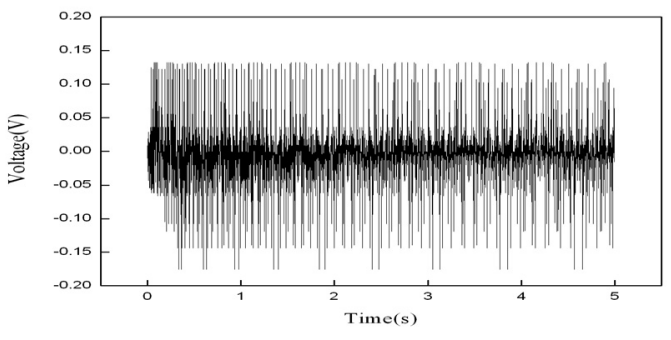

(a) Experiment no. V-1

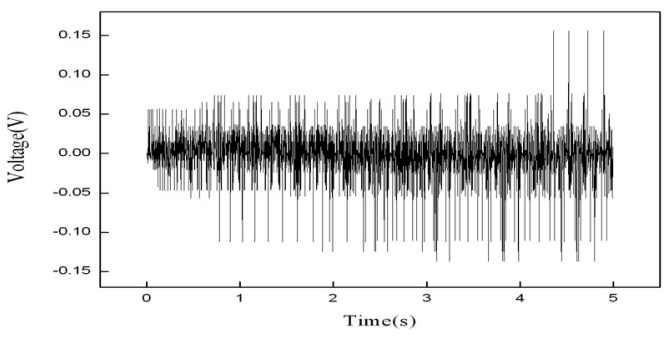

(b) Experiment no. V-2

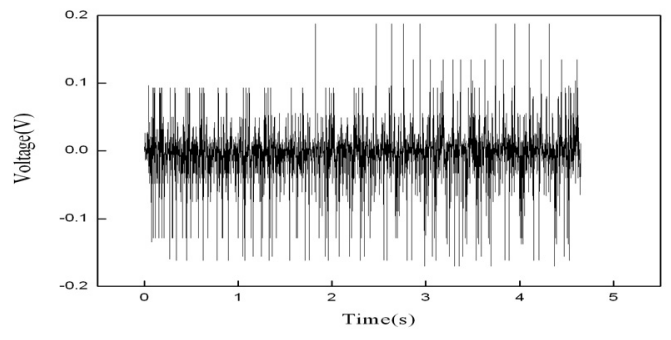

(c) Experiment no. V-3

Fig. 11 AE raw signal of MAP verification experiments

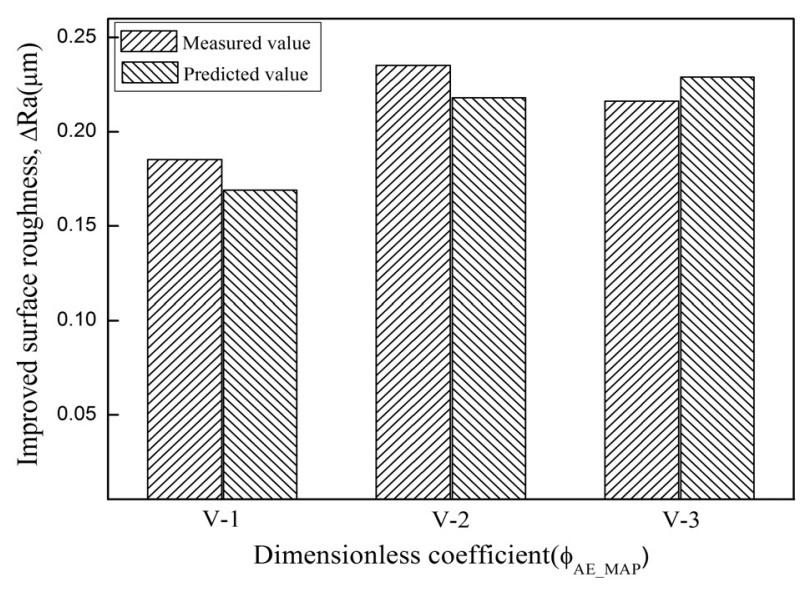

Fig. 12 Comparison of measured and predicted value

선정하고, 표면거칠기 향상 값을 목표값으로 하여 신경회로망 시스템으로 분석하였다. Fig. 13은 입력함수에 따른 평균 제곱 오차와 목표값과 출력값의 회귀도를 나타내었다. 분석의 결과 로 9번째 반복횟수에서 목표값에 수렴하였고, 상관계수 $\mathrm{R}$ 은 1 에 가까운 값을 나타내었다. 따라서 자기연마 공정변수와 무차 원계수를 동시에 입력함수로 사용하여 분석하면 매우 높은 신
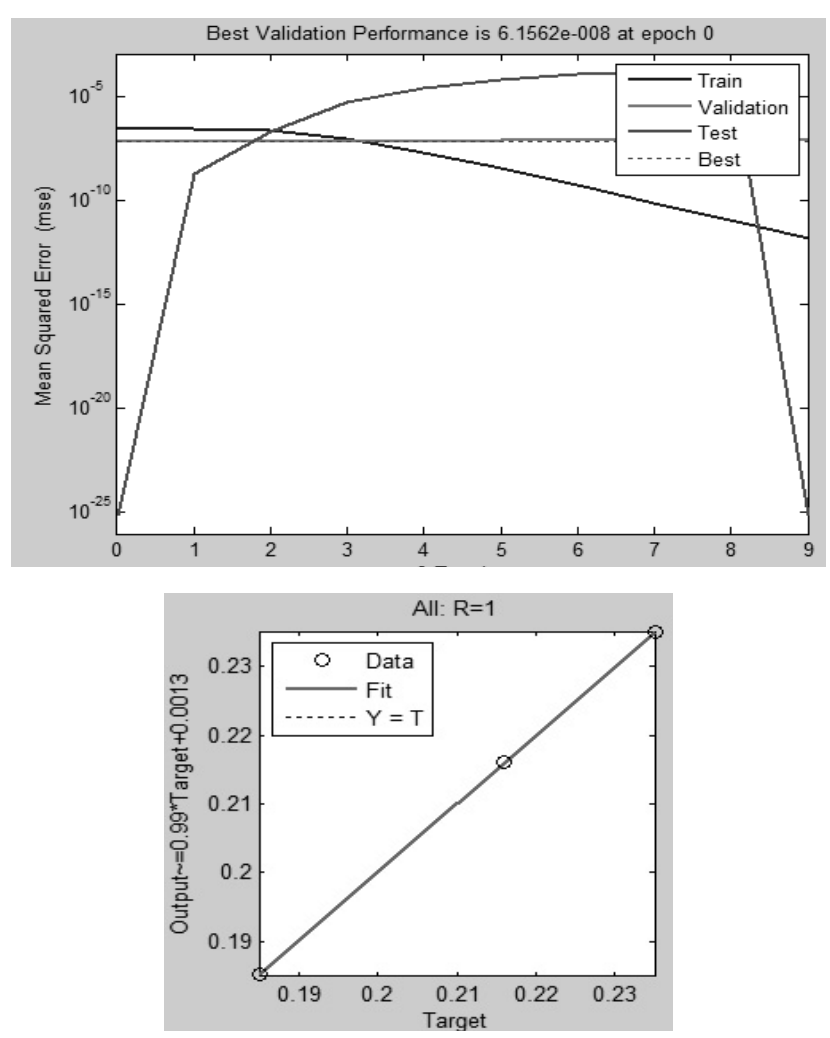

Fig. 13 Mean square error and regression of experiments

뢰수준을 나타낸다는 것을 알 수 있었다. 즉, 자기연마 공정에 $\mathrm{AE}$ 센서를 활용한 모니터링 시스템을 자기연마 공정에 적용하 여 표면거칠기 향상 값의 온라인 예측이 가능함을 확인하였다.

\section{5. 결 론}

본 논문에서는 금형강 소재인 NAK80의 효율적인 연마를 위하 여 자기연마법을 제안하였고, 자기연마 공정 중에 발생하는 $\mathrm{AE}$ 신호를 획득하여 온라인으로 표면거칠기 향상 값을 예측할 수 있 는 예측식을 제안하고, 오차율과 신경회로망 시스템을 통하여 자 기연마 모니터링 시스템을 분석하여 아래와 같은 결론을 얻었다.

(1) $\mathrm{AE}$ 신호로부터 구해지는 무차원계수 $\left(\phi_{A E M A P}\right)$ 를 이용하 여 자기연마가공에서 표면거칠기 향상정도를 온라인으로 예측할 수 있는 예측식 $p(x)=-1.21 \times \phi_{A E . M A P}+1.543$ 을 제안하였다.

(2) 신경회로망 시스템에 자기연마 가공변수와 $\mathrm{AE}$ 신호의 무 차원계수를 동시에 입력함수로 사용하여 학습한 경우에 오 차율 $5 \%$ 이내의 매우 높은 신뢰수준을 나타내었고, 목표값 에 가장 빠른 수렴을 보인다는 것을 확인하였다.

(3) 자기연마가공에서 $\mathrm{AE}$ 모니터링 시스템을 적용하면 표면 거칠기 향상 값을 온라인으로 예측이 가능함을 확인하였다. 


\section{후 기}

이 논문은 2012년도 정부(교육과학기술부)의 재원으로 한국연구 재단의 지원을 받아 수행된 기초연구사업임(No. 2012-0001716).

\section{References}

(1) Wen, D. C., 2009, "Microstructure and Corrosion Resistance of the Layers Formed on the Surface of Precipitation Hardenable Plastic Mold Steel by Plasma-nitriding," Applied Surface Science, Vol. 256, No. 3, pp. 797 804.

(2) Singh, D. K., and Jain, V. K., 2005, "Analysis of Surface Texture Generated by a Flexible Magnetic Abrasive Brush," Wear, Vol. 259, No. 7 12, pp. 1254 $\sim 1261$.

(3) Kwak, J. S., 2009, "Enhanced Magnetic Abrasive Polishing of Non-ferrous Metals Utilizing A Permanent Magnet," International Journal of Machine Tools and Manufacture, Vol. 49, No. 7 8, pp. 613 618.
(4) Kim, S. R., Kim, H. Y., Kim, J. U., Yoon, H. M., and Ahn J. H., 2005, "Relation of AE and Polishing Parameters for Polishing Process Monitoring," Journal of the Korean Society of Precision Engineering, Vol. 22, No. 10, pp. 90 98.

(5) Juang, S. C., Tarng, Y. S., and Lii, H. R., 1998, “A Comparison between the Back-propagation and Counterpropagation Networks in the Modeling of the TIG Welding Process," Journal of Materials Processing Technology, Vol. 75, No. 1 3, pp. 54 62.

(6) Kim, C. W., Choi, K. J., Jung, S. H., and Hong, D. S., 2009, "Development of a Web-based Remote Monitoring System for Evaluating Degradation of Machine Tools Using ART2," Transactions of the Korean Society of Machine Tool Engineers, Vol. 18, No. 1, pp. 42 49.

(7) Kim, Y. S., and Kwon, W. T., 2011, "Determination of Optimal Cutting Conditions in Milling Process Using Multiple Design of Experiments Technique," Journal of Korean Society of Manufacturing Technology Engineers, Vol. 20, No. 3, pp. 232 238. 